\title{
Assessment of Tear Production among Adults with Pterygium
}

\author{
Azuamah, Y.C. ${ }^{1}$, Abadom, N.P. ${ }^{2}$, Esenwah, E.C. ${ }^{3}$, Ikoro, N.C. ${ }^{4}$, Megwas, A.U. ${ }^{5}$ \\ ${ }^{1-5}$ Department of Optometry, Federal University of Technology, Owerri, Nigeria \\ Corresponding Author: Azuamah, Y.C.
}

DOI: https://doi.org/10.52403/ijrr.20220217

\begin{abstract}
Pterygium is a wing-shaped fibrovascular proliferation that develops over the conjunctiva. This study was carried out to compare the tear production among adult patients with pterygium and a control group. A total of 92 subjects were used for this study which comprised of 52 pterygium subjects and 40 control groups. The tear film production was measured using Schirmer's test strips and the length of pterygium was measured using PD rule. Visual acuity and external examination were taken on all subjects before tear production measurement. Results showed that for pterygium subjects, tear production of $0-10 \mathrm{~mm}$ had the highest frequency of $35(67.31 \%)$ followed by 11 $20 \mathrm{~mm}$ with the frequency of $15(28.85 \%)$ and 21 $-30 \mathrm{~mm}$ with the least frequency of $2(3.85 \%)$. For control subjects, tear production of 11 $20 \mathrm{~mm}$ had the highest frequency of $24(60 \%)$ followed by $21-30 \mathrm{~mm}$ with the frequency of $7(1.75 \%), 0-10 \mathrm{~mm}$ with frequency of $6(15 \%)$ and $31-40 \mathrm{~mm}$ with the least frequency of $3(7.5 \%)$. The mean tear production values of pterygium and control subjects were $10.40 \pm 5.65 \mathrm{~mm}$ and $17.65 \pm 7.83 \mathrm{~mm}$ respectively. SPSS version 23 data analysis using the independent sample T-test at 0.05 level of significance showed a significant reduction $(\mathrm{P}<$ $0.05)$ in tear production among pterygium subjects. It was concluded that people with pterygium are more susceptible to dry eye. Public awareness of pterygium and the use of lubricating eye drops were recommended.
\end{abstract}

Key Words: Pterygium, Dry Eye, Tears, Tear film, Tear production, Conjunctiva

\section{INTRODUCTION}

Pterygium is a wing-shaped, vascular, fleshy growth that originates from the conjunctiva and can spread to the corneal limbus and beyond. ${ }^{[1]}$ Pterygium is relatively common in the general population and can vary from small, atrophic quiescent lesions to large, aggressive, rapidly growing fibrovascular lesions that can distort the corneal topography, and in advanced cases, obscure the optical center of the cornea. ${ }^{[2]}$ Some studies [3] have reported that pterygium could directly result in localized elevation of the conjunctiva and uneven tear distribution, thereby leading to abnormal dry eye and tear dynamics. Pterygium is associated with numerous risk factors which include ultraviolet radiation (UV), viral infection, hereditary factors, immunological factors, aseptic inflammations, environmental irritation from wind, dust or trauma, smoke, and ocular dryness. [4] Ultraviolet radiation remains a wellestablished pathogenic factor of pterygium based on epidemiological evidence.

Clinically, pterygium can be divided into four parts; the cap, head, neck and body. The cap or leading edge is a flat zone on the cornea that consists mainly of fibroblasts that invade and destroy the Bowman's membrane. The head is triangular in shape and is firmly adherent to the cornea. The neck is the part of the pterygium lying on the limbus and the body is a fan-shaped expansion from the neck, consisting of epithelium, connective tissue and blood vessels. ${ }^{[5]}$ Pterygium arises in the 
interpalpebral fissure as an elevated, fleshy mass on the bulbar conjunctiva near the limbus in its early stage. Engorged radial vessels may appear over the pterygium and adjacent conjunctiva and usually signal a period of rapid growth. The bulbar conjunctiva may become increasingly taut as the pterygium enlarges toward the limbus. ${ }^{[6]}$ Symptoms of burning sensation, irritation, lacrimation, and foreign body sensation may accompany the growth of a pterygium onto the cornea. Significant astigmatism may be induced as sectoral corneal steepening occurs. [7] The astigmatism is often irregular and may lead to decreased vision. As the apex approaches the visual axis, glare and decreased contrast sensitivity appear. In severe cases, symblepharon formation may limit ocular motility and result in diplopia. The lesion may remain quiescent for the remainder of the patient's life or resume growth again at a later time. Older, static lesions are often associated with an arcuate line of iron deposition in the superficial cornea immediately central to the cap known as Stocker's line. ${ }^{[8]}$

The tear film is the fluid covering the cornea and conjunctiva. ${ }^{[9]}$ It is also called the pre-corneal film. The tear film is responsible for providing a smooth refractive surface for clear vision, maintaining the health of the corneal and conjunctival epithelia and acting as the first line of defense against microbial infection. [10] Tear film provides ocular surface comfort through continuous lubrication. Tears are continually replenished from the inferior tear meniscus by blinking. This counters the forces of gravity and evaporation on the volume of the precorneal tear film and protects corneal and conjunctival epithelial cells from the shear forces exerted by the eyelids during blinking. ${ }^{[11]}$ Tears are secreted by accessory (basal secretion) and main (reflex secretion) lacrimal glands. Reflex secretion is in response to sensation from the cornea and conjunctiva, probably produced by evaporation and breakup of tear film. ${ }^{[9]}$
Afferent pathway of this secretion is formed by fifth nerve and efferent by parasympathetic supply to lacrimal gland. Tear production is approximately 1.2 microliters per minute, with a total volume of 6 microliters and a turnover rate of $16 \%$ per minute. ${ }^{[11]}$

Tears flow downwards medially across the surface of the eyeball to reach the lower fornix and then through the lacus lacrimalis in the inner canthus, from where they are drained by lacrimal passage into the nasal cavity. This is brought about by an active lacrimal pump mechanism constituted by fibers of the orbicularis (especially Horner's muscle) which are inserted on the lacrimal sac. ${ }^{[9]}$ When the eyelid closes during blink, contraction of these fibers distends the fundus of the sac, create therein a negative pressure which siphons the tear through punctum and canaliculi into the sac. When the eyelids open, the Horner's muscle relaxes, the lacrimal sac collapses and a positive pressure is created which forces the nasolacrimal duct into the nose. ${ }^{[12]} \mathrm{A}$ reduction in tear production may result in dry eye symptoms such as burning sensation, redness, eye sensitivity to smoke, difficulty keeping the eye open, photophobia, and reflex burning due to corneal irritation. ${ }^{[13]}$ Pterygium can cause symptoms of discomfort, induced corneal aberrations that compromise visual acuity and patient's quality of life. The prevalence of pterygium varies worldwide; global prevalence was estimated to reach higher numbers in topical region. In tropical African countries such as Nigeria, pterygium constitutes a significant proportion of ocular surface disorders encountered in clinical practice and it is sometimes associated with some degree of vision loss. Pterygium has a high prevalence of $19.3 \%$ in Nigeria. ${ }^{[14]}$ Pterygium growth and development has also been shown to be associated with tear film instability. [15] Hence the aim of this study was to investigate the level of tear production among adults with pterygium. 


\section{MATERIALS AND METHODS}

This study was a clinical study carried out at the Department of Optometry Teaching Clinic, Federal University of Technology, Owerri, Imo state, Nigeria. An informed consent was gotten from all the subjects who were part of the study. The demographic information of the subjects was collected and their health history was also taken to rule out any systemic disease which might affect tear film production values. Visual acuity was taken using Snellen's visual acuity chart. External eye examination was conducted to rule out any ocular surface infections among the subjects. The tear film production of subjects with pterygium and control group was measured using the schirmer test strips and the pterygium length was measured with an PD rule.

\section{STATISTICAL METHODS}

The data obtained from the study was uploaded into the Statistical Package for Social Sciences (SPSS) version 23 software. The independent-Sample $\mathrm{T}$ test was used to test the hypothesis at 0.05 level of significance and $95 \%$ confidence interval.

\section{RESULTS}

A total of 92 subjects comprising 50 pterygium cases and 40 control subjects were used for this study. Table 1 showed a comparison of the age distribution among pterygium and control subjects. For pterygium subjects, age group 20-31 had the highest frequency of 22(42.31\%), followed by age group 31-40 with frequency of $15(28.85 \%)$, age group $41-50$ had the frequency of $11(21.15 \%)$, age group above 50 had the least frequency of 4(7.69\%). For control subjects, age group 20-31 had the highest frequency of $28(70.0 \%)$ followed by age group of 31-40 and 41-50 which had the same frequency of 5(12.50\%), and age group above 50 had the least frequency of $2(5.00 \%)$. Table 2 showed that pterygium length ranging from 1.61-1.80 had the highest frequency of $18(34.62 \%)$ followed by 1.41-1.60 with a frequency of
$11(21.15 \%), 1.21-1.40$ had a frequency of $9(17.31 \%), 1.81-2.00$ had a frequency of $8(15.38 \%)$ and $1.00-1.20$ had the least frequency of $6(11.54 \%)$. Table 3 showed the distribution of tear production among pterygium and control subjects. For pterygium subjects, tear production range of $0-10$ had the highest frequency of $35(67.31 \%)$ followed by $11-20$ with the frequency of $15(28.85 \%)$ and 21 - 30 with the least frequency of $2(3.85 \%)$. For control subjects, tear production range of $11-20$ had the highest frequency of $24(60 \%)$ followed by 21-30 with the frequency of $7(1.75 \%), 0-10$ with a frequency of $6(15 \%)$, and 31-40 with the least frequency of $3(7.5 \%)$. Table 4 showed the descriptive statistics of tear production among subjects with pterygium and control measured in millimeters using the Schirmer strips. The number of pterygium subjects was 52 with a range of 27 , minimum value of 3 , maximum value of 30 , mean value of 10.40 , standard deviation of 5.65 and variance of 32.09 while the number of controls were 40 with a range of 31 , minimum value of 4 , maximum value of 35 , mean value of 17.65 , standard deviation of 7.83 and variance of 61.31 . Table 5 showed that among the clinical features experienced by the pterygium subjects, tearing had the highest frequency of $12(23.07 \%)$, itching was $8(15.38 \%)$, redness had a frequency of $7(13.46 \%)$, and foreign body sensation had the lowest frequency of $5(9.61 \%)$. From SPSS version 23 data output, data analysis using the independent sample T-test at 0.05 level of significance and $95 \%$ confidence interval revealed a significant difference $[\mathrm{P}(0.00)<$ 0.05] in tear production values between people with pterygium and control group.

Table 1: Age distribution among pterygium cases and control subjects

\begin{tabular}{|l|l|l|}
\hline $\begin{array}{l}\text { Age group } \\
\text { (Years) }\end{array}$ & $\begin{array}{l}\text { Pterygium } \\
\mathbf{n}(\boldsymbol{\%})\end{array}$ & $\begin{array}{l}\text { Control } \\
\mathbf{n}(\boldsymbol{\%})\end{array}$ \\
\hline $20-31$ & $22(42.31)$ & $28(70.00)$ \\
\hline $31-40$ & $15(28.85)$ & $5(12.50)$ \\
\hline $41-50$ & $11(21.15)$ & $5(12.50)$ \\
\hline Above 50 & $4(7.69)$ & $2(5.00)$ \\
\hline Total & $52(100.00)$ & $40(100.00)$ \\
\hline
\end{tabular}


Table 2: Distribution of length of pterygium among subjects

\begin{tabular}{|l|l|l|}
\hline $\begin{array}{l}\text { Pterygium Length } \\
\text { (cm) }\end{array}$ & $\mathbf{n}$ & \% \\
\hline $1.00-1.20$ & 6 & 11.54 \\
\hline $1.21-1.40$ & 9 & 17.31 \\
\hline $1.41-1.60$ & 11 & 21.15 \\
\hline $1.61-1.80$ & 18 & 34.62 \\
\hline $1.81-2.00$ & 8 & 15.38 \\
\hline Total & 52 & 100 \\
\hline
\end{tabular}

Table 3: Distribution of tear production among pterygium and control subjects

\begin{tabular}{|l|l|l|}
\hline $\begin{array}{l}\text { Tear Production } \\
(\mathbf{m m})\end{array}$ & $\begin{array}{l}\text { Pterygium } \\
\mathbf{n}(\boldsymbol{\%})\end{array}$ & $\begin{array}{l}\text { Control } \\
\mathbf{n}(\boldsymbol{\%})\end{array}$ \\
\hline $0-10$ & $35(67.31)$ & $6(15.00)$ \\
\hline $11-20$ & $15(28.85)$ & $24(60.00)$ \\
\hline $21-30$ & $2(3.85)$ & $7(17.50)$ \\
\hline $31-40$ & $0(0.00)$ & $3(7.50)$ \\
\hline Total & $52(100.00)$ & $40(100.00)$ \\
\hline
\end{tabular}

Table 4: Descriptive statistics of tear production (mm) among subjects with pterygium and a control group

\begin{tabular}{|l|l|l|l|l|l|l|l|}
\hline Subjects & n & Range & Min & Max & Mean & S.D & Variance \\
\hline Pterygium & 52 & 27 & 3 & 30 & 10.40 & 5.65 & 32.09 \\
\hline Control & 40 & 31 & 4 & 35 & 17.65 & 7.83 & 61.31 \\
\hline
\end{tabular}

Table 5: Clinical features among pterygium subjects

\begin{tabular}{|l|l|l|}
\hline Clinical Features & $\mathbf{n}$ & \% \\
\hline Redness & 7 & 13.46 \\
\hline Itching & 8 & 15.38 \\
\hline Tearing & 12 & 23.07 \\
\hline Foreign Body Sensation & 5 & 9.61 \\
\hline
\end{tabular}

\section{DISCUSSION}

Pterygium is a common disease of the ocular surface characterized by the invasion of fibrovascular tissue from the bulbar conjunctiva onto the cornea and it is sometimes associated with some degree of vision loss. The main objective of this study was to compare tear production in adult subjects with pterygium and a control group. The study showed a wide length of pterygium of above $1.60 \mathrm{~cm}$ in 18 subjects while a mild length of 1.00 to $1.20 \mathrm{~cm}$ in 6 subjects. This clinically suggests a possible growth in pterygium overtime probably due to exposure of subjects to predisposing conditions. The mean tear production in pterygium cases was $10.40 \pm 5.65$ with the control groups showing a higher mean value of 17.65 \pm 7.83 . Hence, the mean tear production values were significantly higher among the control subjects. This was corroborated in several studies ${ }^{[14-17]}$ where people with pterygium where found to have lower tear production values. This study showed complaints of tearing, itching, foreign body sensation and redness among the pterygium subjects. In a study conducted by Wanzeler et al. ${ }^{[15]}$ on how ocular surface parameters correlate to the presence of pterygium and also possible impact of pterygium on tear film, it was found that pterygium had a great direct impact on the lacrimal film alterations. This supports the findings of this study herein on distorted and reduced quality tear film production. Lawan et al. ${ }^{[16]}$ in his study on astigmatic effect of pterygium, found that the presence of pterygium induces an astigmatic error on the eyes. This suggestively could be due to the distortion of tear film layer causing a non-uniform refraction at the tear-corneal interface. This indirectly supports the study herein on the effect of pterygium on tear production as regards the slight reduction in tear quality but excessive production of reflex tears which could be due to sensation on the lacrimal tissues by the pterygium.

A study by Drvmvrvprasadarao ${ }^{[18]}$ showed that abnormal tear film function was associated with pterygium, and pterygium excision improved tear film function. Hence pterygium reduced basal tear production. This was supported by studies conducted by Manhas et al. ${ }^{[19]}$ and Mustafa et al. ${ }^{[20]}$ who conducted their studies on changes in tear film functions in patients with pterygium before and after pterygium excision, and on evaluating differences in tear osmolality and tear film parameters between pterygium affected and healthy eyes respectively. Although a few studies were done to evaluate the association of occupation with pterygium nevertheless, Achigbu and Ezepue ${ }^{[14]}$ in their study found that there were high rates of pterygium prevalence among commercial riders in South-east Nigeria and this was seen in this study with commercial riders making up a good number of the pterygium subjects. The study further associated this prevalence with duration of riding over 5 years, which most likely may be the reason for the progressive increase in length of pterygium as seen in 
this study with 18 subjects having over $1.6 \mathrm{~cm}$ length of pterygium. Narayani and Shreshthal [21] assessed the basal tear secretion using TBUT and Schirmer's test and found that dry eyes occurred in $54 \%$ of pterygium cases but only $26 \%$ of normal eyes which is also supported by studies done by Ishioka et al. ${ }^{[17]}$ Hence presence of pterygium was seen to reduce basal tear production. Pterygium is most likely the reason for this difference.

\section{CONCLUSION}

In conclusion, the study showed that the tear production values among people with pterygium was significantly lower than that for the control group. Thus, people with pterygium are more susceptible to dry eye. Public awareness campaigns to enlighten the public about pterygium and its implications should be intensified. Lubricating eye drops were also recommended for people with pterygium who may suffer from dry eye.

\section{Acknowledgement: None}

\section{Conflict of Interest: None}

\section{Source of Funding: None}

\section{Ethical Approval: Approved}

\section{REFERENCES}

1. Aminlari A, Singh R, Liang D. Management of Pterygium. 2010; Available at: http://www.aao.org/eyenet/article/managem ent-of-pterygium-2. [Retrieved $16^{\text {th }}$ January, 2020].

2. Ali RT, Ali AB. The effect of pterygium on cornea thickness, corneal curvature, tear volume and intra ocular pressure. Al Baser Int J Ophthalmol. 2017; 4(4): 109-103.

3. Abdelfattah NS, Dastiridou SR, Lee OL. Non-invasive imaging of tear dynamic in eyes with ocular disease. J Cor Extern Dis. 2015; 34: 548-552.

4. Zhou WP, Zhu YF, Zang B, Qui W, Yao YF. The role of ultraviolet radiation in the pathogeneses of pterygia. PubMed J. 2016; 14: 3-15.
5. Manhas A, Gupta D, Manhas R, Kumar D, Kotwal SK, Manhas G. Tear film functions in patients with pterygium. Int J Cont Med Resources. 2017; 4(5): 1199 - 1203.

6. Ginger-Eke HA, Ogonnaya CE, Ezis CN. Pterygium: recent trends and perspectives. A review of pathogenesis and current management options. Nig J Ophthalmol. 2018; 26(2): 89-98.

7. Avisar R, Loya N, Yassur Y, Weinberger D. Pterygium induced corneal astigmatism. Isr Med Assoc J. 2000; 2: 14 - 15.

8. Mohammed-Salih PA, Sharif AF. Analysis of Pterygium size and induced Corneal Astigmatism. J Cornea Ext Dis. 2008; 27: 434-438.

9. Khurana AK. Comprehensive Ophthalmology. 5th Ed. New Dehli: New Age International Publishers. 2012; 389 391.

10. Azuamah YC, Esenwah EC, Ikoro NC, Megwas AU, Ugwuoke GI, Ogbonna U. Comparison of the effect of topical $0.5 \%$ Timolol maleate and 4\% Pilocarpine on ocular tear film $\mathrm{pH}$ of patients with primary open angle glaucoma. Int J Res Rev. 2019; 6(6): $445-450$.

11. Foster JB, Lee WB. The tear film; Anatomy, structure and function. 2015; Available at: http://www.clinicalgate.com/thetearfilmanatomy-structure-and-function. [Retrieved on 18th January, 2020].

12. Kanski JJ, Bowling B. Clinical ophthalmology: a systematic approach. 7th Ed. Melbovine: Elsevier Saunders. 2011; 231-240.

13. Kucuk E, Yilmaz U, Zor KR. Corneal epithelial damage and impaired tear film functions in patients with inflamed pterygium. 2018; Available at: https://www.hindawi.com/journals/joph.

[Retrieved on 17th September, 2019].

14. Achigbu EO, Ezepue UF. The prevalence and severity of pterygium among motorcycle riders in South-east Nigeria. Gh Med J. 2014; 48(3): 153-157.

15. Wanzeler ACV, Barbosa IAF, Duarte B, Barbosa EB, Borges DA, Alves M. Impact of pterygium on the ocular surface and meiboamian glands. Plos One J, 2019; 14(9): 21-39.

16. Lawan A, Hassan S, Ifeanyichukwu EP, Yahaya HB, Sani RY, Habib SG, Shuaib A, Eme O. The astigmatic effect of pterygium 
in a tertiary hospital in Kano, Nigeria. Ann Afr Med. 2018; 17:7-10.

17. Ishioka M, Shimmura S, Yagi Y, Tsubota K. Correlation between dry eye and pterygium. J Opthalmol. 2001; 215(3): 209211.

18. Drvmvrvprasadarao MS. Effect of pterygium on tear film. J Den Med Sc. 2017; 16(3): $61-63$.

19. Manhas A, Gupta D, Manhas R, Kumar D, Kotwal SK, Manhas G. Tear film functions in patients with pterygium. Int J Cont Med Resources, 2017; 4(5): 1199 - 1203.

20. Mustafa O, Arslan B, Erdur SK, Gulkilik G, Kocabora SM. Tear osmorality and tear film parameters in patients with unilateral pterygium. J Cor Ext Dis. 2014; 33(11): 1174-8.

21. Narayani RB, Shreshtha SP. Assessment of tear secretion and tear film instability in cases with pterygium and normal subjects. Nepal J Ophthalmol. 2013; 5(9): 16-23.

How to cite this article: Azuamah, Y.C., Abadom, N.P., Esenwah, E.C. et.al. Assessment of tear production among adults with pterygium. International Journal of Research and Review. 2022; 9(2): 117-122. DOI: https://doi.org/ 10.52403/ijrr.20220217

$* * * * * *$ 